\title{
Análisis de Redes Sociales y el Impuesto al Hospedaje: Estudio del arte
}

\author{
Esthela Carrillo Cisneros
}

\section{Resumen}

Partiendo de la metodología a través del Análisis de Redes Sociales (ARS) en esta investigación se identifica una red de stakeholders y actores que colaboran en el proceso del Impuesto al Hospedaje desde la recaudación y gestión hasta su aplicación a través de la promoción turística. Para esto, se parte primeramente del análisis a un marco normativo aplicable en la política pública del citado gravamen en la entidad federativa de Sonora, México. Los resultados refieren la creación de una matriz de relaciones con fundamental importancia en esferas colaborativas entre el Sector gobierno, la Oficina de convenciones y visitantes, iniciativa privada y Cámaras de Comercio, Servicios y Turismo, Cámaras de Industria y Confederaciones (no lucrativas); identificándose además actores de mayor dominio a efectos del logro de objetivos; a la vez, se perciben áreas de oportunidad para que la política fiscal optimice; ya que de manera aislada y sin esfuerzos conjuntos, difícilmente se lograrían acciones de impacto en el turismo como incidente de desarrollo local a través de la promoción turística.

\section{Introducción}

A efectos de estudiar fenómenos económicos y sociales, la información pública es un elemento indispensable en la realización de estudios investigaciones por parte de usuarios del sector privado, académico y del público en general, así como para evaluar los resultados de la gestión pública.

A la vez, cuando se habla de impuestos es ineludible identificar la relación entre el Estado y la sociedad, la cual se articula a través del desarrollo y las decisiones para ejercer los recursos recaudados de los diversos sectores, que en este caso, se aborda el sector turismo.

El variado porcentaje de recaudación del impuesto al hospedaje establecido en cada una de las entidades federativas de México, la reciente transición del manejo de este impuesto del municipio hacia el estado, la baja fiscalización, así como las escasas investigaciones en México en materia de redes de colaboración acerca de este impuesto, propicia el interés para el análisis de las redes a efectos de identificar las relaciones de colaboración entre los diversos actores y stakeholders que inciden en la gestión administrativa de este impuesto.
En este sentido, este trabajo aborda el impuesto al servicio de hospedaje como parte de una política pública y el cual es ejercido a través de la promoción y publicidad turística para el estado de Sonora.

Para promocionar nacional e internacionalmente de manera competitiva los productos y destinos de Sonora, se requiere de un trabajo conjunto entre los actores de la actividad turística a través de la innovación activa que estimule al turista a visitar la entidad federativa; por lo que en este trabajo se evalúa la importancia y características de las conexiones que se dan entre los que componen, lo que permite visualizar las acciones de cooperación en materia de promoción turística y su incidencia en el desarrollo turístico local y cuya representación inicial constituye una matriz adyacente. Los objetivos específicos son:

1. Identificar actores, partes involucradas y acciones interdependientes en la recaudación, gestión pública y aplicación del impuesto al hospedaje en la promoción turística.

2. Presentar de manera gráfica las conexiones relacionales y regularidades; visualizando la cooperación y transferencia de recursos.

3. Mostrar el aporte teórico, metodológico de la metodología a través del Análisis de Redes Sociales (ARS).

La relevancia de abordar uno de los elementos que contribuye al desarrollo local turístico refiere a que este sector aportó directamente el $8.7 \%$ del PIB a la economía mexicana en 2015, lo cual representa una de las mayores participaciones entre los países de la Organización para la Cooperación y el Desarrollo Económico (OCDE, 2015). En las cifras a nivel local, el estado de Sonora representa uno de los destinos turísticos de relevancia en México, encontrándose en el doceavo lugar en oferta de alojamiento, respecto a treinta y dos entidades federativas de México.

A la vez, el servicio de alojamiento por el cual se genera el impuesto al hospedaje, representa el 9.1\% del producto Interno Bruto Turístico. 
En tal sentido, en el proceso continuo de permanecer posicionado y por ende contribuir a la derrama económica del estado, se requiere una articulación activa de las partes involucradas principales que son el sector gobierno, sector privado y las oficinas de convenciones y visitantes, siendo esta última quien facilita la articulación entre ambos sectores.

En relación a esto, el recurso financiero que se aplica en la promoción turística del estado proviene de la recaudación del Impuesto al Servicio de Hospedaje, en cuya política pública establece a través del artículo 10 de la Ley de Hacienda Estatal (2017), que el 90\% recaudado serán aportados a los fideicomisos que operan las Oficinas de Convenciones y Visitantes, para promoción y publicidad turística. El 10\% restante, será utilizado por el Estado en áreas de administración, cumplimiento de obligaciones y fiscalización del Impuesto; de acuerdo a lo dictado en la Ley de Hacienda Estatal de Sonora.

\section{Marco referencial y conceptual}

En el análisis de la literatura existente relativa al Análisis de Redes Sociales (ARS), se corrobora que esta metodología es cada vez más utilizada en ámbitos multidisciplinares, a la vez, se confirma que las relaciones de colaboración entre el ámbito públicoprivado juegan un papel fundamental en el cumplimiento de objetivos.

En relación a esto, el ARS circunscribe el análisis cualitativo y cuantitativo como método para determinar una representación derivada de algún análisis a través de una herramienta electrónica; los que permite identificar estructuras sociales que resultan de acciones interdependientes $\mathrm{y} / \mathrm{o}$ relaciones que se dan no solo entre actores, sino también entre individuos e instituciones; lo que permite investigar interacciones a nivel micro y macro.

"La denominación 'la ciencia de las redes' la debemos a la reciente incorporación de físicos a un campo conocido hasta ahora como 'análisis de redes sociales' (ARS en castellano o SNA, Social Network Analysis en inglés" (Molina, 2004). En tal sentido, "una red social contiene dos elementos esenciales: una población de actores y por lo menos una relación que sea medible, definida para cada par de actores" (Freeman 1989).

En una de las contribuciones Molina (2001), manifiesta:
[..] el análisis de redes sociales estudia relaciones específicas entre una serie definida de elementos (personas, grupos, organizaciones, países e incluso acontecimientos). A diferencia de los análisis tradicionales que explican, por ejemplo, la conducta en función a la clase social y la profesión, el análisis de redes sociales se centra en las relaciones y no en los atributos de los elementos (p.13).

Señala Hanneman (2002) respecto a las redes en cuyo análisis se contempla el estudio de las relaciones entre individuos de forma multidisciplinaria:

\section{[..] Las diferencias en cómo los individuos están} conectados puede ser extremadamente útil para entender sus atributos y comportamiento. Muchas conexiones significan a menudo que los individuos se exponen todavía a más y más diversa información. Individuos bien conectados pueden ser más influyentes y pueden estar más influenciados por otros. Las diferencias en el grado de conexión de poblaciones completas pueden tener también importantes consecuencias.

Desde la perspectiva del ARS "el entorno social puede expresarse como patrones o regularidades en las relaciones entre las unidades interactuantes"

(Wasserman y Faust, 1999:3). En complemento, la teoría de redes "utiliza dos tipos de herramientas matemáticas para representar información sobre los patrones de relaciones entre actores sociales: grafos y matrices" (Hanneman, 2002).

Con relación a esto, antecedentes básicos del análisis de redes se relacionan en este documento a través de ciertos autores que pusieron las bases sobre este tema. Por una parte está la Teoría de la Gestalt y Teoría del Campo, las cuales formaron las bases para el análisis de redes. A la vez, la Teoría de Grafos forma uno de los cimientos más importantes para la representación gráfica de las redes creada hacia 1736 por Leonhard Euler (Reynoso, 2008: 19), surgiendo de la necesidad de explicar matemáticamente la imposibilidad de resolver el acertijo de "los puentes de Kônigsberg", donde se intentar trazar un camino para cruzar siete puentes sin pasar dos veces por el mismo. 
Fig. 1. Orígenes de la Teoría de Redes.

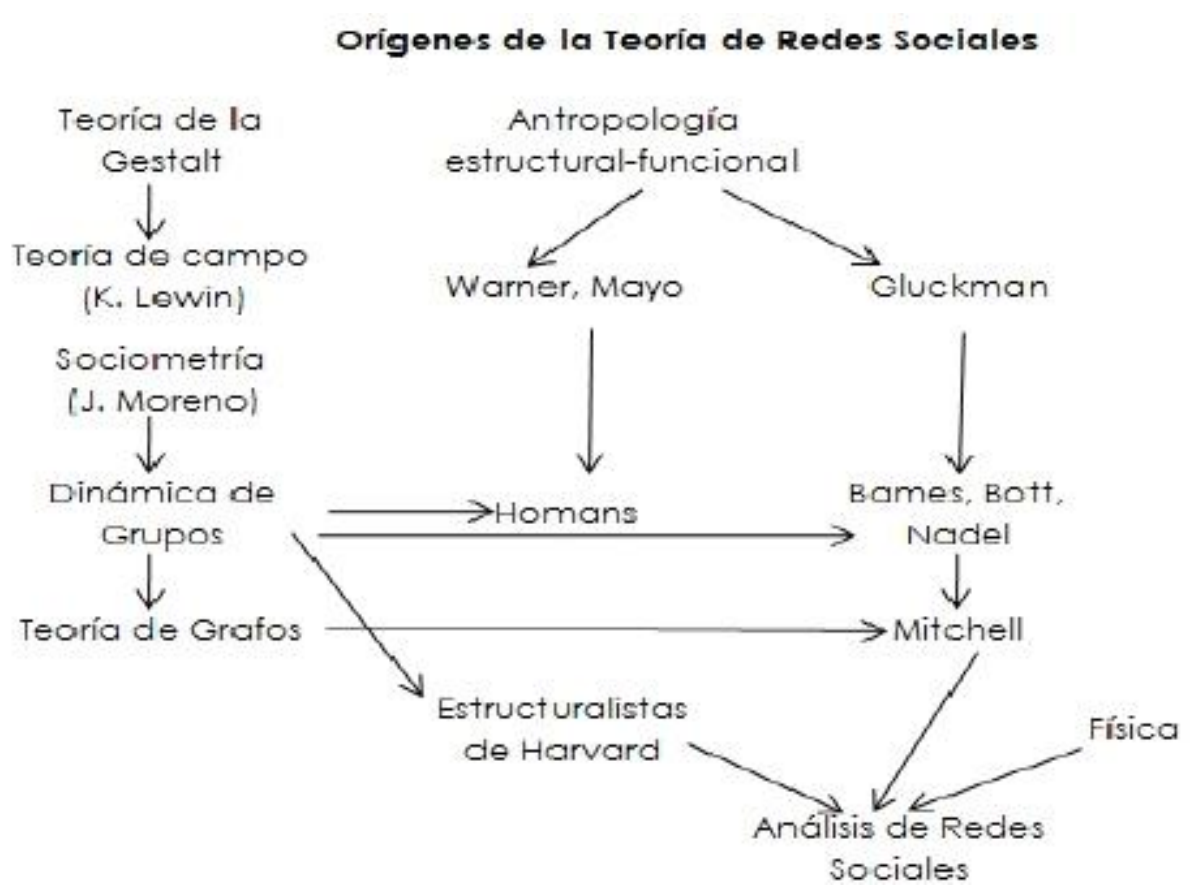

Fuente: Scott, J. (2017). Social Network Analysis. Sage Pub. 4th.Ed. pag. 13

Por el lado de la sociología en estudios de organizaciones (estructuras de subgrupos y conocimiento de grupos informales) están las contribuciones de Elton Mayo desde 1926; a través de los estudios de Warner (1929) donde se identifican diversos tipos de cliques que se forman en las estructuras de las redes. Derivaciones posteriores como las de Homans (1961), surgen proposiciones sociológicas que se aplican en estudios de las redes.

\section{(Ver Figura 1)}

Otras contribuciones que no se pueden dejar de lado son las de Simmel (1972-1999) donde se identifican los elementos de las estructuras a través de las diadas, triadas y la interacción social o estudios económicos enfocados en las tipologías de la interacción. A la vez, Scott. (2017:1-37) desde el año 1991 contribuyó con estudios de grupos dinámicos, además de las contribuciones de la escuela antropológica de Manchester (1954-1972) de la cual derivan las conceptualizaciones de la red abordando la teoría del conflicto más que la cohesión como parte del análisis de redes relacionales. Moreno (1934); Harary (1963) con la teoría de grafos y modelos matemáticos en sistemas sociales en los años 50 y 60; y Adler (1975).
La vigencia y relevancia en ARS actualmente se encuentran presentes a través de "International Network for Social Network Analysis (INSNA) por sus siglas en inglés, la cual es una asociación profesional de investigadores avocados al análisis de redes sociales fundada por Barry Wellman en 1977; y a nivel Iberoamérica está el portal electrónico de la revista académica hispana REDES y el laboratorio de redes en la Universidad Autónoma de México, quienes abordan el análisis de redes sociales con perspectiva reticular.

\section{Conceptos de redes sociales}

El abordaje de representar a través de estructuras de red a los individuos como puntos o nodos (personas) y representar las interacciones entre ellos unidos por líneas o (vínculos) se observan con Moreno (1934) por el lado de la sociometría.

También hay análisis de red social a través del autor Mitchell (1969) y Boot (1957), entendida como vínculo existente entre conjunto de individuos. A la vez, las redes admitidas como campos sociales que incluyen en su contexto un territorio, sistema ocupacional y relaciones personales analizadas por Barnes (1954). 
En los trabajos de Erdós (1959-60), sobre redes aleatorias, que incluye el modelo matemático (ER) para la generación de grafos aleatorios, donde se contempla que todo puede ser visto como una colección de nodos conectados al azar y que pueden ser medidos.

A la vez, Granovetter (1973) presenta reflexiones avanzadas sobre análisis de redes referente a los lazos fuertes y lazos débiles entre conjuntos de personas. Posteriormente, los investigadores Wasserman \& Faust (1994), contribuyen al término señalando que "el análisis de redes sociales se centra sobre las relaciones entre entidades sociales y sobre las pautas implicaciones de estas relaciones".

En lugar de analizar las conductas, actitudes, o creencias de los individuos, el ARS centra su atención sobre entidades sociales o actores en interacción de unos con otros, y en cómo estas interacciones constituyen un marco o estructura que pueden ser estudiadas en sí mismas (Wellman, 1998). Por lo tanto, "la clave para conjeturar un modelo de red social, a partir de una situación real, estriba en conceptualizar relacionalmente tal situación. Es decir, en establecer qué tipo de lazos existen entre las entidades sociales en cuestión" (Faust, 2000).

En tal sentido, los datos de red se definen por actores y por relaciones (o por nodos y por vínculos); a la vez, las relaciones son datos reticulares tiene que ver con qué lazos o relaciones serán medidos en los nodos seleccionados; por lo que cualquier conjunto de actores puede estar conectado con diferentes tipos de lazos y relaciones (Hanneman, 2002).

Por lo antepuesto, haciendo énfasis que es necesario utilizar ciertos elementos básicos al trabajar con el ARS, uno de éstos son los "nodos o actores", Hanneman (2002), nos explica que

[..] "los datos de red que se definen por actores y por relaciones (o por nodos y por vínculos). La parte de los datos de la red correspondiente a nodos o actores debería ser bastante precisa. Otros enfoques empíricos en ciencias sociales también trabajan en términos de casos, sujetos o elementos representativos y semejanzas. [..] Los nodos o actores incluidos en estudios que no son de redes, tienden a ser el resultado de un muestreo probabilístico independiente. Los estudios de redes intentan incluir todos los actores que se muestran en un límite (que a menudo se muestra de forma natural).
Por su parte, Newman (2003), contribuye con el término señalando que "una red es un conjunto de ítems, los cuales llamaremos vértices, o algunas veces, nodos con conexiones entre ellos que se llaman ligas" y continúa señalando Hanneman (2002), que "con frecuencia los estudios de redes no utilizan muestras en absoluto, al menos en el sentido convencional. Al contrario, intentan incluir todos los actores en una población o poblaciones determinada(s). Por supuesto, las poblaciones incluidas en un estudio de red pueden ser una muestra de un conjunto grande de poblaciones".

De acuerdo a Freeman (2004), el ARS posee características que lo distinguen de otros tipos de análisis estructurales:

1) Está motivado por una intuición estructural basada en la búsqueda de lazos que vinculan, actores sociales; 2) se basa sistemáticamente en evidencia empírica; 3) recurre a grafos y al análisis, morfológico de los mismos como herramienta heurística central; 4) confía en el uso de modelos matemáticos, o computacionales para la formalización y generalización de sus proposiciones.

A la vez, Ruiz (2005), señala que "la clave para conjeturar un modelo de red social a partir de una situación real estriba en la conceptualización relacional de tal situación".

Es de relevancia considerar que hay tres propiedades importantes en el análisis de una red: "La centralidad, las posiciones que ocupan los actores y los subgrupos a que pertenecen. Las interpretaciones de la red varían según el nivel de análisis: por actores, por pares de actores, por triadas, por subconjuntos o por el conjunto total de actores de la red" (Burt 1980; Marsden y Laumann 1984; Wasserman y Faust 1994).

En este contexto, Herrero (2000), expone y concentra los conceptos fundamentales de ARS refiriendo de manera relevante el trabajo que antecede de Scott (2017), en dicho trabajo repasar las cuestiones básicas en tomo a las que se ha desarrollado el análisis de redes, exponiendo los conceptos elementales, así como los términos que los designan y propone una traducción de los mismos. "A la hora de construir una terminología en español para el análisis de redes no es sólo un problema de traducción, no se trata únicamente de encontrar una palabra equivalente que sea adecuada. 
Se trata de establecer una terminología precisa y sin ambigüedades". Para esto, incluye en su glosario las definiciones de grafos, centralidad y centralización, subgrupos, componentes, núcleos, cliqués, círculos y posiciones.

Hay que señalar además, que Wasserman y Faust (1994-2013) en su obra titulada Análisis de Redes Sociales [Métodos y Aplicaciones], aborda los conceptos fundamentales del análisis de redes sin menoscabo a los distintos capítulos que claramente contribuyen desde aportaciones para las recogidas de datos hasta los modelos estadísticos de interacción.

Términos y fundamentos básicos que permiten describir y representar visualmente las estructuras que se general con el ARS también son expresadas por Ramírez (2016), a través del libro titulado análisis de redes sociales para el estudio de la gobernanza y las políticas públicas, donde comprensiblemente refiere a Hanneman y Riddle, (2005); Knoke y Yang, (2007) y a Wasserman y Faust, (1994-2013); éstos últimos a través de su obra titulada Análisis de Redes Sociales [Métodosy Aplicaciones] abordan los conceptos fundamentales del análisis de redes sin menoscabo a los distintos capítulos que claramente contribuyen desde aportaciones para las recogidas de datos hasta los modelos estadísticos de interacción;

En resumen, el contar con terminología especializada para analizar las redes sociales y sus datos, es de relevancia para abordar problemas de investigación que de otra manera, sería difícil a través de un marco tradicional.

Al utilizar la teoría de redes es posible comprender el comportamiento de los actores en su entorno y además procurar propuestas de acciones dirigidas al innovar procesos administrativos eficientes y eficaces, mediante entidades sociales constituidas por actores y los cuales pueden ser individuos, corporaciones o unidades sociales colectivas Zizaldra (2010).

Finalmente, los nodos que forman parte de la red del presente estudio implican partes involucradas entre instituciones e individuos; por lo que se define que el tipo de red que se utilizará es la "red de dos modos". Wasserman y Faust (2013) describen las redes bimodales que "incluye mediciones para dos conjuntos de actores de diferentes tipos y un conjunto de acontecimientos".
A través del ARS es posible examinar actores procedentes de conjuntos diferentes; como los estudios de Galaskiewicz (1985) y Galaskiewicz y Wasserman (1989), quienes analizaron conjunto de actores de corporaciones residentes del área, de organizaciones sin ánimo de lucro, cuyo presupuesto operativo provenían de contribuciones del sector público.

Una vez identificada la relevancia e investigaciones que han dejado vestigio en el contexto del Análisis de Redes Sociales, no se puede omitir que dentro de esta metodología es necesario conocer el análisis cuantitativo.

\section{Redes de política pública y gobemanza}

De manera más específica, en la presente investigación se aborda el estudio de la reticularidad que existe desde la recaudación, gestión y aplicación del Impuesto al Servicio de Hospedaje; gravamen que el sector hotelero le retiene al turista por el servicio de alojamiento y el retorno se refleja a través de las erogaciones en promoción turística.

En tal sentido, refiriendo el impuesto que se analiza en el presente trabajo, se dirige a que éste forma parte de una política pública, misma que como señala el Diccionario Jurídico (2017):

Una política pública puede ser definida como una intervención deliberada del Estado para corregir o modificar una situación social o económica que ha sido reconocida como problema público. También suele llamarse con ese nombre a las decisiones transversales que regulan la actuación interna de los gobiernos y que están destinadas a perfeccionar la gestión pública: regulaciones que atañen a la forma en que los poderes públicos realizan las atribuciones que les han sido conferidas y que, en consecuencia, pueden llegar a determinar la eficacia, la eficiencia o la legitimidad de sus resultados.

En complemento Hernández (2006) señala una definición de política fiscal:

[..] Instrumento básico de intervención y regulación de la actividad económica por parte del Estado, con miras a mejorar el bienestar económico, social y el desarrollo económico; los principales ingresos de la política fiscal son por la vía de impuestos, derechos, productos, aprovechamientos, y el endeudamiento público interno y externo. 


\section{Texto 2.}

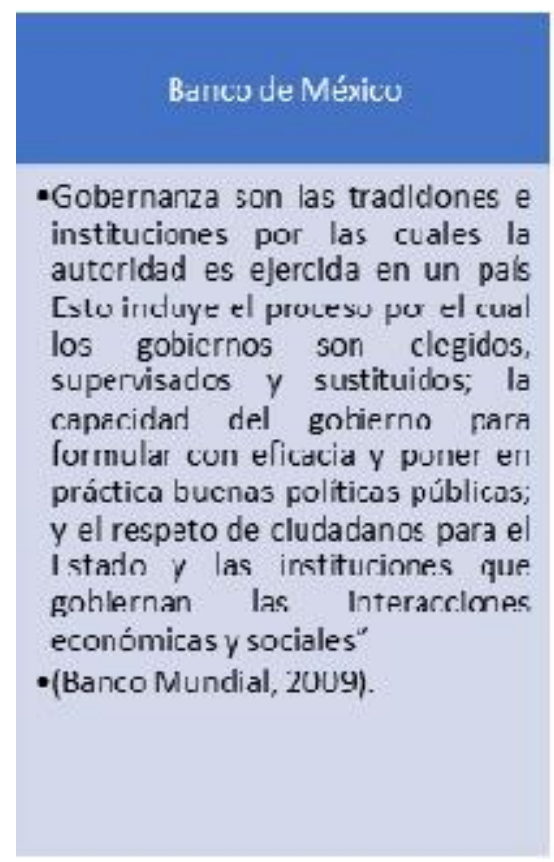

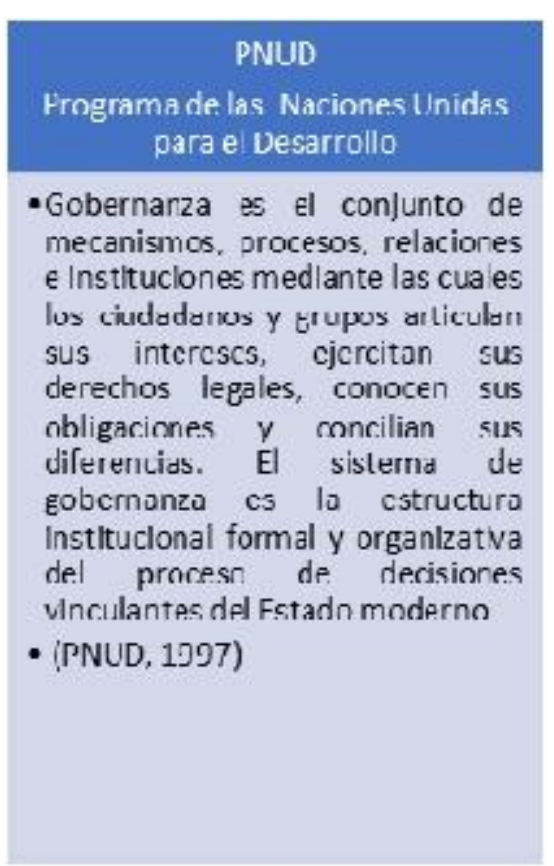

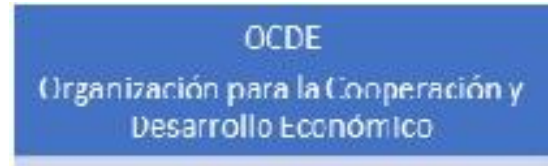

- Gobernanza es el empleo de la autoridad politica y el ejercicio de control en una socledad, en relación con la conducción cle sus recursos paro el desarrollo económico y social, además de considerar el papel de las auluidades públicas lanto en el cstableciniento del cntorno $\mathrm{cn}$ cl cual operan los agentes eronńmirns mmo en la determlnadión de la dstriburkín de los beneficios, asi como la naturaleza de las relacionles erilte gobernante y gobemadc. -(CCDE, 1995).

Fuente: Gobernanza para el sector turismo y su medición, Duran (2013).

En el campo de las finanzas públicas, la política fiscal como acción del Estado busca el equilibrio entre lo recaudado por impuestos y otros conceptos y los gastos gubernamentales.

A la vez, el glosario adjunto al documento publicado por la Organización Mundial de Turismo (Duran, 2013:37) titulado Gobernanza para el sector turismo y su medición, incluye las siguientes definiciones:

Red: Concepto polisémico que puede ser usado para describir a los diversos actores interdependientes implicados en la prestación de servicios públicos, así como para referir a las formas o estructuras sociales que conformadas en forma autónoma tienen capacidad de autogobierno y se coordinan para intercambiar sus múltiples recursos para la consecución de sus objetivos y maximizar su influencia sobre resultados.

Redes de políticas públicas se refiere a los patrones más o menos estables de relaciones sociales entre actores interdependientes que se forman alrededor de los problemas y/o programas de políticas públicas.
Por otra parte, anteriores investigaciones realizadas de las políticas públicas concernientes a un ámbito local se encuentran Vargas (2011), Porras (2007), Martínez (2015). Asimismo, hay trabajos que discuten y analizan el papel que juega el gobierno en redes de políticas públicas, (Porras, 2012). En este contexto y con la visión de generar estrategias aplicables a la gestión o dirección de redes de políticas, entre otros están Ramírez (2016), Sánchez (2008), Zabaleta (2008). A la vez, los investigadores Di-Maggio y Powell (1991), consolidan avances teóricos, identifican y precisan ambigüedades, a la vez que desarrollan argumentos sofisticados sobre el vínculo entre patrones institucionales y formas de estructura social.

En otros estudios relativos a la gestión pública predominan conceptos que han sido utilizados resaltando el concepto de redes de gobernanza (Jones, Hesterly y Borgatti, 1997; Provan y Kenis, 2008).

La gobemanza consiste en "un nuevo significado del gobierno, refiriéndose [específicamente] a un nuevo proceso de gobernación; redes interorganizacionales auto-organizadas caracterizadas por la interdependencia, el intercambio de recursos, las reglas del juego y la autonomía significativa del Estado". (Rhodes, 1997:15). 
En este contexto, el documento publicado por la OMT (2013:4) "Gobernanza para el sector turismo y su medición" concentra el concepto relativo a la gobernanza de principales fuentes: (Ver Texto 2)

Por tanto, las redes de gobernanza, las describe Rhodes (2000), indicando que "es un concepto descriptivo utilizado para ilustrar la interdependencia y las diversas relaciones que existen entre organizaciones públicas, privadas y civiles o no gubernamentales".

Para esto, Sorensen y Torfing (2005) concretan la gobernanza de una red de actores basada en algunos elementos:

1) una articulación horizontal relativamente estable de interdependencia entre actores que son operacionalmente autónomos

2) Los actores en esta red interactúan a través de negociaciones y no de relaciones jerárquicas (relaciones coordinadas más que dirigir a los actores)

3) La interacción tiene lugar dentro de un marco normativo, cognitivo e incluso imaginario

4) El marco de actuación es en cierta medida autorregulada y

5) La red contribuye a la producción de utilidad pública dentro de una o más áreas sustantivas de política pública.

En otra investigación, Blair (2002) resalta la red de organizaciones públicas, lucrativas y no lucrativas que se relacionan a efectos de promover el desarrollo económico. A la vez, Choi (2007), puntualiza el enfoque de red como una estructura, resaltando la importancia de las redes informales de la política y la corrupción.

De acuerdo a los antecedentes analizados, se resume que las redes han sido definidas como relaciones entre individuos, entre organizaciones y relaciones entre ambas. Weber y Khademian (2008) concuerdan al afirmar que las redes se definen por "relaciones de intercambio permanente entre las organizaciones, individuos y grupos". A la vez, Towsend (2004) analiza las redes como medio para que las organizaciones o individuos puedan alcanzar objetivos comunes mediante la colaboración.

EI estudio llevado a cabo entre los diversos autores, permite contextualizar y robustecer el ARS resaltando la diversidad de partes involucradas y actores como organizaciones públicas, no gubernamentales y privadas (homogéneos y heterogéneos); a la vez de evaluar las interacciones existentes entre los diversos niveles de gobierno, organismos

internacionales, nacionales, locales y la sociedad; así como entender las relaciones de servidores públicos que desempeñan alguna actividad central.

En términos generales, los estudios anteriores coadyuvan a visualizar áreas de oportunidad y necesidades de cambios deseables en alguna estructura de colaboración, incluso tomar las redes como modelos de contraste de gestión que mejore el desempeño de las organizaciones públicas genere propuestas de mejora al resto de los participantes de la red.

En tal sentido, las referencias anteriores forman parte de la contextualización de la interacción entre los actores en los que se requiere mayor transparencia y rendición de cuentas, así como la incorporación de redes público-privadas en la evaluación de una política pública; por lo que para este fin aún existen importantes retos afines, por lo que las redes contribuyen a la mejora del entendimiento sobre la capacidad del gobierno de actuar a través de redes de política pública cuyos objetivos y resultados deben estar dirigidos a un bien colectivo en sinergia con los colaboradores del proceso.

La noción de organizar la acción pública asume que el papel del gobierno es dar dirección al comportamiento de los actores públicos, privados y sociales; además enfatiza que el gobierno no puede controlar del todo a estos actores ni obligarlos a rendirle cuentas (Sorensen y Torfing, 2005).

\section{Redes, Stakeholders y Actores en el Impuesto al Servicio de Hospedaje}

El impuesto al servicio de hospedaje es un gravamen creado desde el año 2002 para generar recursos para la autopromoción turística de los diversos destinos del estado de Sonora, al igual que en el resto de las entidades federativas de México. Para esto, es a través de la Ley de Ingresos y Presupuestos de Ingresos donde se estipula la proyección de cobro anual fiscal, y cuyo mandato legal establecido en la Ley de Hacienda Estatal establece su recaudación pero también su aplicación para ser ejercido en promoción y publicidad turística.

Por lo antepuesto, este impuesto forma parte de la naturaleza del fenómeno turístico implícito en un esquema como parte de un ingreso local del Estado que cobra, administra y ejerce el impuesto como responsable de conducir el desarrollo económico local, a través de 
estructuras, conocimientos y experiencia que impacta en todo el territorio, permitiendo generar y ejercer a través de los quince años de la vigencia de este impuesto, recursos para la realización de campañas de publicidad turística, nacionales e internacionales, mercadotecnia, eventos de promoción y relaciones públicas de los destinos turísticos de Sonora

Al interior del Estado, los diversos municipios con vocación turística se involucran como parte de la gestión administrativa de los recursos provenientes del impuesto al hospedaje, a través de comités técnicos del fideicomiso del impuesto donde participan miembros de las instancias públicas y privadas involucradas en la actividad turística, como lo son representantes de los Ayuntamientos, la Comisión de Fomento al Turismo del Gobierno del Estado (COFETUR) y del sector privado, específicamente con hoteleros del sector.

\section{Redes con actores heterogéneos}

En la construcción de la reticularidad es importante identificar que la red de dos modos o red bimodal se deriva por actores cuya heterogeneidad proviene de las diferencias entre los diversos colaboradores que participan tanto en la administración del impuesto como la promoción turística.

EI analizar la red de actores heterogéneos permite visualizar y comprender como la gestión gubernamental crea y da forma a redes de colaboración a través de la legislación y la implementación de políticas públicas.

Las condiciones para que exista una red de políticas públicas se deben reconocer bajo ciertas condiciones, por lo que Arenilla y Sánchez (2011) concretan cinco puntos fundamentales:

[..] en primer lugar, reconocer un marco institucional idóneo para la consolidación de redes de políticas públicas; en segundo lugar, se debe distinguir cuál es la naturaleza y los tipos de interacciones de las redes, en tercero, conocer qué grado de institucionalización presentan, en cuarto lugar, en qué medida la estructura de la red condiciona los resultados de los programas/políticas; y por último, qué incidencia ha tenido el proceso en la mejora del capital social de los actores.

Lo anterior, permite una integración de actores en la promoción turística y la propia gestión del impuesto; lo que reconoce hacer del turismo de Sonora un eje rector en una de sus actividades económicas, atendiendo además las vocaciones turísticas de cada Municipio.
En este contexto, en el resumen ejecutivo de Estudios en Turismo de la Política Turística de México (2017:1819), se resalta la importancia de las colaboraciones entre los diversos sectores a través de los siguientes puntos:

Fortalecer los vínculos entre política, producto y promoción, así como promover un enfoque más participativo y una orientación de mercado de las políticas. Adoptar estrategias dirigidas a buscar la colaboración con el sector privado para fomentar una participación más activa e institucionalizada en la formulación y mejora del impacto de las mismas. Se debe considerar la posibilidad de establecer un Consejo Nacional de la Industria Turística que actúe como interlocutor principal de la industria en materia de políticas. Fortalecer el sustento de información que apoya el desarrollo de políticas. Mejorar la integración,

disponibilidad y el uso de estadísticas sólidas del turismo para orientar la formulación de políticas, guiar la implementación, apoyar el seguimiento y la evaluación. Fortalecer la relación entre proveedores estadísticos y usuarios, incluyendo el Instituto Nacional de Estadística y Geografía (INEGI), el Banco de México y la Secretaría de Turismo.

Para esto, se parte del análisis normativo vigente y aplicable al presente estudio el cual se integra principalmente con el examen a la Ley de Hacienda Estatal (2017), Ley de Presupuesto de Egresos y Gasto Público Estatal (2017), Cuenta Pública del Estado (2015), Comité Técnico, así como leyes federales como la Ley General de Turismo (2017), Reglamento de la Ley General de Turismo (2017); que de manera directa dictan acciones en materia turística en coordinación con el Estado.

Por lo tanto, una vez identificado el mandato legal de recaudación del impuesto, se analiza su aplicación obligatoria en promoción y publicidad turística, por lo que es la Ley General de Turismo (2017), en su capítulo III artículo 9 [de la promoción turística]: "Corresponde a los Estados y al Distrito Federal, de conformidad con lo dispuesto en esta Ley y las leyes locales en materia turística, las siguientes atribuciones: $X$. Coadyuvar en la instrumentación de las acciones de promoción de las actividades y destinos turísticos con que cuenta; XI. Promover el impulso de las micro, pequeñas y medianas empresas turísticas". 
Figura 2. Stakeholders y Actores en la recaudación, gestión y aplicación del Impuesto al Hospedaje.

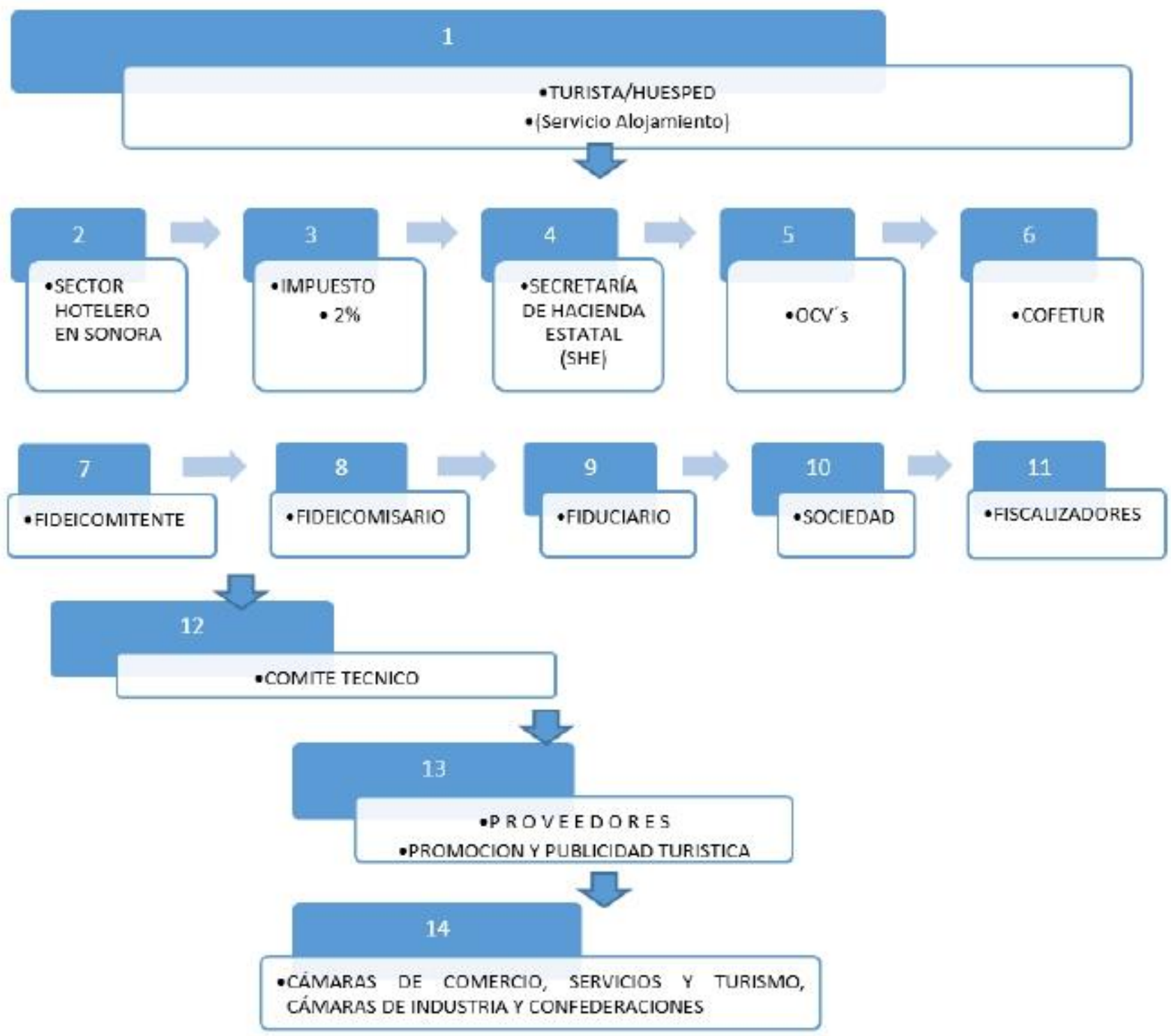

Fuente: Elaboración propia basada en la identificación de stakeholders y actores en la recaudación, gestión y aplicación del Impuesto al Hospedaje.

En esta misma ley, en su título IV Capítulo I, artículos 37 y 38 [de la promoción y fomento al turismo], se indica que "los Estados, los Municipios y el Distrito Federal deberán coordinarse con la Secretaría para el desarrollo de las campañas de promoción turística en territorio nacional y el extranjero.
En tal sentido, a continuación se identifican de inicio, los actores interesados y el rol que desempeñan de acuerdo al marco normativo analizado, los cuales deben estar presentes en la gestión, colaboración y aplicación del impuesto al hospedaje. 
Figura 3. Clasificación de establecimientos de hospedaje.

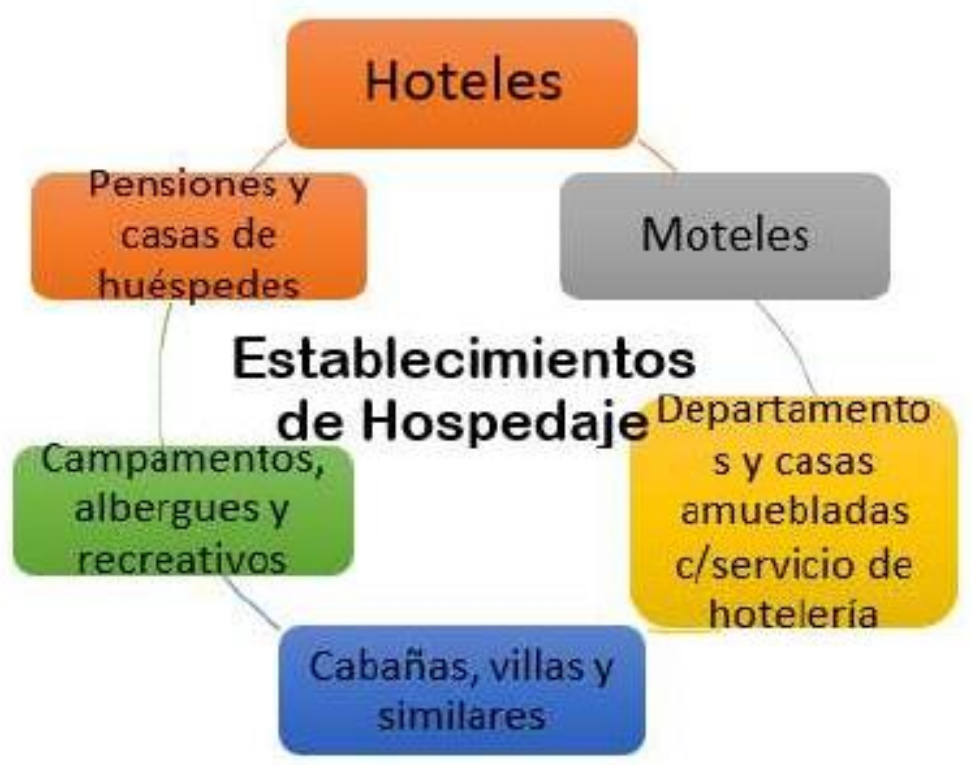

Fuente: Elaboración propia con datos obtenidos de DataTur (2017).

Los stakeholders son elementos fundamentales en este proceso de colaboración entre los diversos sectores. Para esto, la definición aportada por Freeman (1984:25) señala a los actores interesados como "cualquier grupo o individuo que puede afectar o ser afectado por la consecución de los objetivos de una empresa". Años más tarde, este mismo autor reflexiona el concepto como "los grupos e individuos que se benefician o se ven perjudicados, y cuyos derechos son violados 0 respetados, por las acciones de las empresas" (Freeman, 2004:41). A la vez, Agranoff y McGuire (1998), Börzel (1998), Hall (1999), O'Toole (1997) o Provan y Milward (1995) aplican el término stakeholders en estudios de acciones de gobierno y al nuevo papel de las administraciones públicas.

Para esto, además de las revisiones a la normatividad aplicable, manuales de procedimientos, entre otros aplicable al contexto investigado, se consultó además el documento emitido por la Coordinación de Planeación del Consejo de Promoción Turística de México (CPTM, 2014), quien recopiló los términos más comunes utilizados para la operación de las actividades del turismo.
A continuación son identificadas las partes interesadas $y$ actores principales que en un marco normativo deben estar presentes en el proceso, a la vez, se identifican diversas asociaciones que han surgido al paso de los años como parte de mecanismos de coordinación e intereses del empresariales del sector turismo los cuales, contienen representatividad desde local, nacional e internacional. (Ver Figura 2)

El servicio de alojamiento está considerado como parte del proceso de la actividad turística, por lo que los establecimientos de servicios de hospedaje son considerados por el INEGI (2016) como "unidad económica que en una sola ubicación física asentada en un lugar de manera permanente y delimitada por construcciones e instalaciones fijas, combina acciones y recursos bajo el control de una sola entidad propietaria o controladora para proporcionar algún tipo de servicio de hospedaje a terceros, ya sea con carácter mercantil o no".

De acuerdo a la Ley de Hacienda del Estado de Sonora (2017), los ingresos fiscales están determinados por los servicios prestados por hoteles, moteles, tiempo compartido, administración por un tercero de los servicios de hospedaje prestados bajo cualquier modalidad, hostales, casas de huéspedes, villas, búngalos, 
campamentos, paraderos de casas rodantes,

departamentos amueblados con fines de hospedaje para fines turísticos y otros establecimientos que brinden servicios de hospedaje de naturaleza turística.

En este sentido, DataTur (2017), expone la clasificación
De manera detallada en el siguiente cuadro se describe a

cada una de las partes involucradas que se coordinan en el proceso de recaudación, gestión y aplicación en promoción turística del impuesto al hospedaje. (Ver Cuadro 1)

de establecimientos de hospedaje de la siguiente manera: (Ver Figura 3)

Cuadro 1. Descripción de Stakeholders, Actores en el Impuesto al Servicio de Hospedaje.

\begin{tabular}{|l|l|}
\hline \multicolumn{2}{|c|}{ Sector Público } \\
\hline \multirow{5}{*}{ Secretaria de Hacienda } & $\begin{array}{l}\text { Administra los recursos para generar más y mejores } \\
\text { oportunidades a los sonorenses, actuando con estricto apego a } \\
\text { las leyes, reglamentos y otras disposiciones que estas } \\
\text { expresamente le confieren. } \\
\text { Tesorería: Receptor-administrador del 2\% del Impuesto por la } \\
\text { Prestación de Servicio de Hospedaje. } \\
\text { La Secretaría de Hacienda otorga el 90\% de los recursos del } \\
\text { IPSH a las Oficinas de Convenciones y Visitantes (OCV's) y } \\
\text { para la ciudad que no cuente con OCV se transferirán los } \\
\text { recursos a un fideicomiso creado por el ejecutivo estatal, y } \\
\text { también a la Comisión de Fomento al Turismo (COFETUR). } \\
\text { Los recursos ejercidos del fideicomiso serán aplicados en } \\
\text { promoción y publicidad turística. } \\
\text { Fuente: Ley de Hacienda del Estado (2016). }\end{array}$ \\
\hline $\begin{array}{l}\text { Fideicomitente: } \\
\text { Organismo público descentralizado con personalidad jurídica } \\
\text { al Turismo (COFETUR). } \\
\text { promoción y desarrollo de las actividades turísticas en el } \\
\text { Estado. } \\
\text { Ejerce o aplica el impuesto a través de un fideicomiso hacia la } \\
\text { promoción turística de aquellos municipios que no cuentan con } \\
\text { OCV'S. } \\
\text { A través de la Dirección de Promoción y Eventos: Coordinar } \\
\text { campañas de promoción y publicidad con mayoristas hoteleros, } \\
\text { agencias de viajes, oficinas de convenciones y visitantes del } \\
\text { Estado, entre otros, con el propósito de fomentar el turismo } \\
\text { receptivo. } \\
\text { Fuente: Reglamento interior COFETUR (2016). }\end{array}$ \\
$\begin{array}{l}\text { Es la persona física o moral que aporta los recursos } \\
\text { necesarios para operar el fideicomiso (Gobierno del Estado). } \\
\text { Fuente: Ley de Hacienda del Estado (2016) } \\
\text { Gasto público se integra por: fideicomisos públicos } \\
\text { Pagos: Los fideicomisos manejarán sus fondos y harán sus }\end{array}$ \\
\hline
\end{tabular}




\begin{tabular}{|c|c|}
\hline & $\begin{array}{l}\text { pagos a través de sus propias unidades administrativas. } \\
\text { Fuente: Ley del Presupuesto de Egresos y Gasto Público } \\
\text { Estatal (2016) } \\
\text { El fideicomiso presentará al Instituto Superior de Auditoría y } \\
\text { Fiscalización (ISAF) cada año, un informe financiero de la } \\
\text { aplicación y destino de los recursos aportados por el Gobierno } \\
\text { del Estado durante el año inmediato anterior. } \\
\text { Rendición de cuentas } \\
\text { Se realizará un informe trimestral, el cual debe contener: } \\
\text { I.- Ingresos del periodo; } \\
\text { II.- Rendimientos financieros del periodo; } \\
\text { III.- Egresos del periodo y su destino; } \\
\text { IV.- Disponibilidades o saldo del periodo, y } \\
\text { V.- Listado de beneficiarios, en su caso. } \\
\text { La cuenta pública debe incluir un reporte del cumplimiento de } \\
\text { la misión y fines de los fideicomisos. } \\
\text { Fuente: Ley de Hacienda del Estado (2016) }\end{array}$ \\
\hline Fideicomisario. & $\begin{array}{l}\text { Es la persona física o moral que recibe los beneficios de la } \\
\text { operación del fideicomiso (Gobierno del Estado). } \\
\text { Fuente: Ley de Hacienda del Estado (2016) } \\
\text { Gasto público se integra por: fideicomisos públicos } \\
\text { Pagos: Los fideicomisos manejarán sus fondos y harán sus } \\
\text { pagos a través de sus propias unidades administrativas. } \\
\text { Fuente: Ley del Presupuesto de Egresos y Gasto Público } \\
\text { Estatal (2016) }\end{array}$ \\
\hline Fiscalizadores. & $\begin{array}{l}\text { ISAF: Instituto Superior de Auditoría y Fiscalización } \\
\text { Órgano de Fiscalización Superior del Congreso del Estado } \\
\text { para realizar la auditoría de los estados financieros, la revisión } \\
\text { y fiscalización de la cuenta pública del Estado y rendición de } \\
\text { cuentas. } \\
\text { Fuente: Reglamento Interior del ISAF } \\
\text { Fiscalización Superior: Facultad para conocer, revisar, auditar } \\
\text { y evaluar el uso y aplicación de los recursos públicos, de } \\
\text { conformidad con las disposiciones constitucionales y legales, a } \\
\text { cargo del Instituto. } \\
\text { Fuente: Ley de Fiscalización Superior para el Estado de } \\
\text { Sonora (2016) }\end{array}$ \\
\hline
\end{tabular}




\begin{tabular}{|c|c|}
\hline \multicolumn{2}{|r|}{ Sector Privado Empresarial } \\
\hline Sector hotelero (SH): & $\begin{array}{l}\text { Forma parte del conjunto de unidades económicas agrupadas } \\
\text { en el renglón de alojamiento, clasificado por la industria } \\
\text { turística. Fuente: Glosario de Coordinación de Planeación del } \\
\text { Consejo de Promoción Turística de México (CPTM, 2016). } \\
\text { Obligado fiscal en el traslado del impuesto a las personas a } \\
\text { quienes presta el servicio de hospedaje. } \\
\text { Obligado fiscal en el entero del impuesto. }\end{array}$ \\
\hline $\begin{array}{l}\text { Comité Técnico del } \\
\text { Fideicomiso del Impuesto al }\end{array}$ & El fideicomiso contará con un Comité Técnico. \\
\hline \multicolumn{2}{|r|}{ Proveedores Turísticos } \\
\hline Proveedores de Servicio: & $\begin{array}{l}\text { Proveedores de servicios. } \\
\text { Incluye a las empresas que brindan servicios turísticos } \\
\text { básicos y complementarios en una región. Fuente: Glosario de } \\
\text { términos utilizados para la Promoción del Turismo. }\end{array}$ \\
\hline Servicio de Hospedaje. & Integrado por: Un representante de Secretaría de \\
\hline \multicolumn{2}{|r|}{ Organismo No Lucrativo } \\
\hline \multirow[t]{2}{*}{$\begin{array}{l}\text { Oficinas de Convenciones y } \\
\text { Visitantes (OCV's). }\end{array}$} & $\begin{array}{l}\text { Estructura que se encarga, en México, de la promoción de la } \\
\text { oferta turística. } \\
\text { Fuente: Glosario de Coordinación de Planeación del Consejo } \\
\text { de Promoción Turística de México (CPTM,2016). } \\
\text { Figura jurídica que actúa como instrumento para ejercer el } \\
\text { impuesto al hospedaje en promoción turística (Asociación } \\
\text { Civil); con el objetivo de posicionar positivamente el destino } \\
\text { turístico a través de un comité técnico que apoya e impulsa el } \\
\text { proceso de marketing, ventas, servicios y alianzas estratégicas } \\
\text { para el desarrollo y posicionamiento del destino. }\end{array}$ \\
\hline & $\begin{array}{l}\text { Hacienda, uno de la Secretaría de Economía, dos de la } \\
\text { Comisión de Fomento al Turismo y siete vocales del sector } \\
\text { turístico del Estado. } \\
\text { Fuente: Ley de Hacienda del Estado (2016) }\end{array}$ \\
\hline Fiduciario. & $\begin{array}{l}\text { Es la institución bancaria autorizada para administrar los } \\
\text { recursos del fideicomiso. }\end{array}$ \\
\hline
\end{tabular}

Fuente: Ley de Hacienda del Estado (2016). 


\begin{tabular}{|c|c|}
\hline \multicolumn{2}{|c|}{ Sociedad Civil } \\
\hline \multirow{3}{*}{ Turista. } & $\begin{array}{l}\text { Las personas que viajan temporalmente fuera de su lugar de } \\
\text { residencia habitual y que utilicen alguno de los servicios } \\
\text { turísticos. } \\
\text { Fuente: Ley General de Turismo. México (2016). }\end{array}$ \\
\hline
\end{tabular}

\begin{tabular}{|l|l|}
\hline \multicolumn{2}{|c|}{ Instituciones de educación superior } \\
\hline \multirow{3}{*}{ Instituciones educativas. } & $\begin{array}{l}\text { Centros de educación para formar profesionistas con las } \\
\text { competencias y conocimientos requeridos por el mercado } \\
\text { laboral con la pertinencia y vinculación social involucrando } \\
\text { intereses económicos y políticos que finalmente inciden en el } \\
\text { desarrollo del país a través del aporte de investigaciones en los } \\
\text { diversos sectores. }\end{array}$ \\
\hline
\end{tabular}

En complemento a las anteriores partes interesadas en el proceso del impuesto y promoción turística, también están identificados colaboradores de relevancia que forman parte de la red, las cuales, son las cámaras de comercio, de industria y confederaciones, quienes fungen como órganos de consulta y colaboración del Estado, las cuales representan los intereses de los empresarios, ya que el gobierno deberá consultarlas en todos aquellos asuntos vinculados con las actividades que representa, de acuerdo a lo establecido en la Ley de Cámaras Empresariales y sus Confederaciones (2017).

En este contexto, los intereses empresariales del sector turístico y que forman parte del proceso del impuesto al hospedaje y su aplicación hacia la promoción turística son referenciados a continuación:

Cuadro 2. Sector empresarial a través de las cámaras de comercio, industria y confederaciones.

\begin{tabular}{|l|l|}
\hline \multicolumn{2}{|c|}{ Cámaras de Comercio, Servicios y Turismo, Cámaras de Industria y Confederaciones } \\
\hline \multirow{4}{*}{$\begin{array}{l}\text { Son Instituciones de interés público. No tienen fines de lucro. } \\
\text { Representan, promueven y defienden nacional e } \\
\text { Cámaras de Industria } \\
\text { Confederaciones } \\
\text { los servicios y el turismo y colaboran con el gobierno para lograr } \\
\text { el crecimiento socioeconómico, así como la generación y } \\
\text { distribución de la riqueza. } \\
\text { Fuente: Ley De Cámaras Empresariales y sus Confederaciones } \\
(2017)\end{array}$} \\
\hline
\end{tabular}




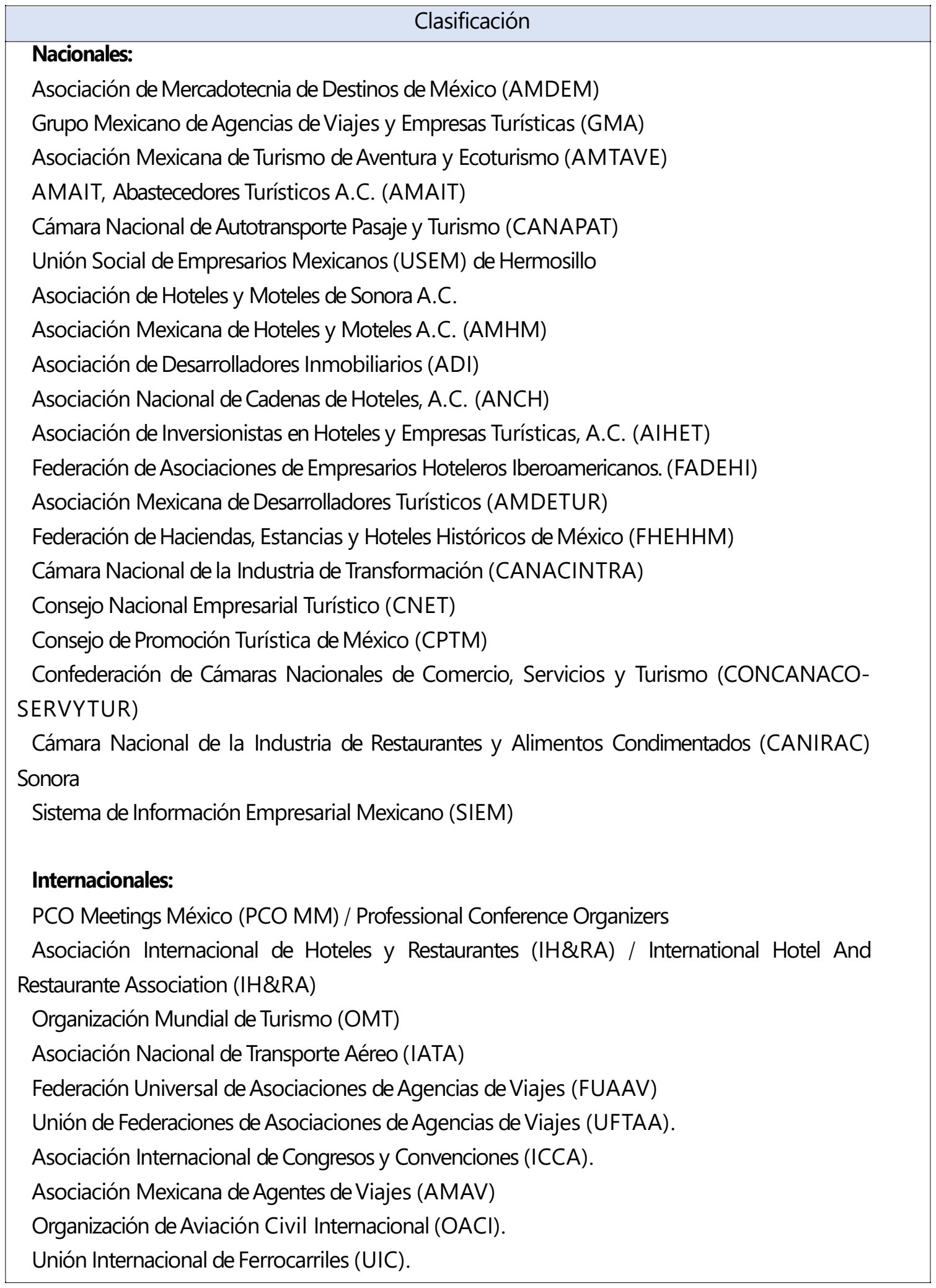


Figura 4. Actividades turísticas que componen el Producto Interno Bruto Turístico.

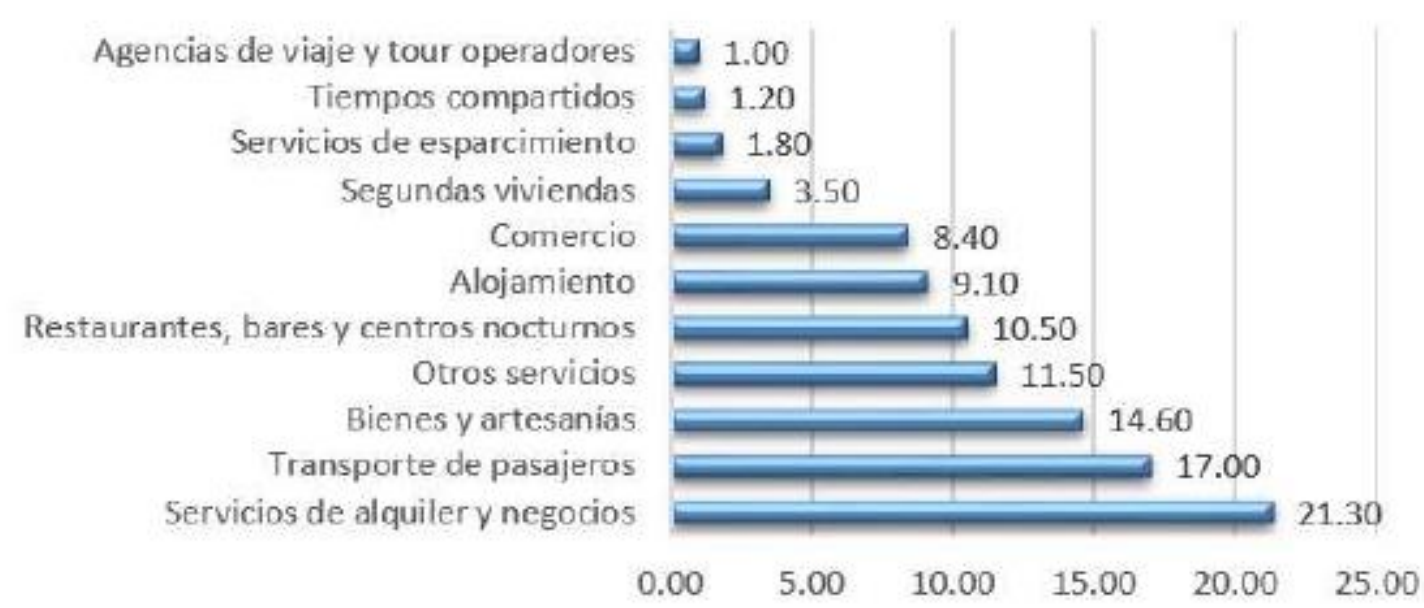

Fuente: Instituto Nacional de Estadística, Geografía e Informática (INEGI,2017) del Producto Interno Bruto Turístico (PIBT) con cifras al 2015.

Figura 5. El impuesto al hospedaje y su aplicación.

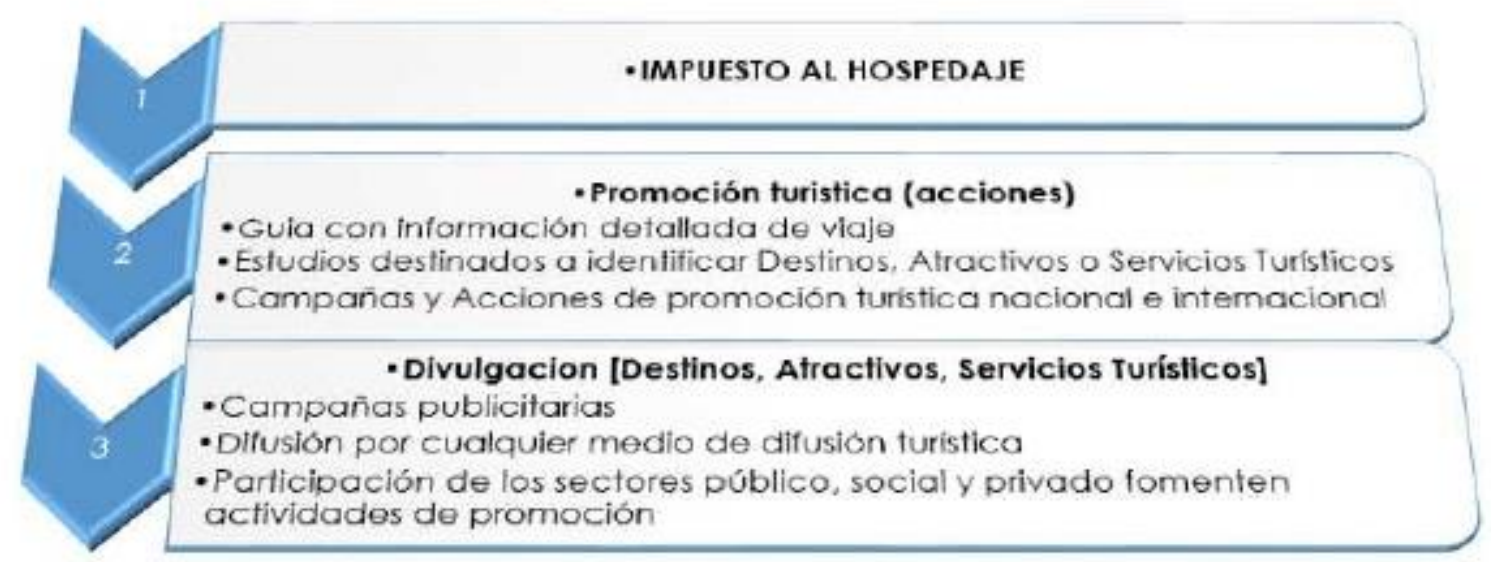

Fuente: Elaboración propia basada en Ley de Hacienda Estatal y Reglamento de la Ley General de Turismo (2016).

En este sentido, resulta relevante como señala Zizaldra (2010):

[...] solo con observar los ámbitos en los que se desenvuelven los actores y stakeholders en turismo, se percibe la necesidad de reciprocidad en acciones concretas o de incentivos, porque sus acciones van desde el nivel global, subglobal, nacional, local y en el destino. La labor se extiende como intermediaria en la actividad no solamente en la administración pública, asociaciones sociales, proveedores de empresas turísticas, estructuras científicas y académicas, sino en los socios público-privados y privado-público, aparte de las sociedades civiles y organismos no gubernamentales.

Respecto a la relevancia de la participación y la necesidad de promover un método abierto de cooperación, el autor Blanco (2006) señala: 
[..] hoy adquiere una especial importancia la cooperación entre los sectores público y privado ("método abierto de cooperación"), la cooperación entre los distintos operadores socioeconómicos y la creación de redes. El rendimiento de una política pública o de un sector determinado depende cada vez más de la compleja interacción de personas y organizaciones, es decir, del modelo organizativo interno y del tipo de red de relaciones con los actores externos.

\section{Metodología}

En esta primera etapa de la investigación, se accedió a información pública, se realizó análisis exhaustivo a normatividad aplicable al contexto a efectos de identificar las principales partes involucradas en la recaudación y gestión del impuesto y su aplicación a través de la promoción y publicidad turística. A la vez, se identificaron actores periféricos al proceso a través de entrevista semiestructurada al director de la Oficina de Convenciones y Visitantes, a la Secretaría de Hacienda (actores directamente involucrados en el proceso), a la Comisión de Fomento al Turismo (COFETUR) y al sector hotelero.

Basada en la información anterior, se construyó el proceso de colaboración de los diversos involucrados, lo que permitió la construcción de una matriz de relaciones y se procesó en el software electrónico Pajek.

\section{Resultados y Conclusiones}

Se destaca que las relaciones obtenidas fueron definidas por las obligaciones establecidas en el marco normativo aplicable, así como la comprobación de actuación en el proceso a través de reuniones realizadas e identificadas a través de las actas oficiales, firmadas y publicadas del comité técnico del fideicomiso, cuyos integrantes provienen del sector hotelero, sector gobierno y ocv estatal.

El comportamiento del desarrollo económico analizado desde el producto Interno Bruto (PIB) turístico (el cual representa el valor de todas las actividades características y conexas del sector), es de gran relevancia para la integración del contexto de las finanzas públicas, lo cual permite una visión oportuna, completa y coherente de la evolución de las actividades económicas del país, para apoyar la toma decisiones.
La valoración de los bienes y servicios que conforman la participación en el sector turístico, se integra de la siguiente manera y como se puede apreciar, el 'alojamiento' contribuye con el 9.10\% dentro del PIB turístico, ubicándose por encima del comercio, servicios de esparcimiento, tiempos compartidos y agencias de viaje y tour operadores. (Ver Figura 4)

En tal sentido, los servicios de alojamiento están considerados como actividades turísticas, por lo que los establecimientos de servicios de hospedaje son considerados por el INEGI (2016) como "unidad económica que en una sola ubicación física asentada en un lugar de manera permanente y delimitada por construcciones e instalaciones fijas, combina acciones y recursos bajo el control de una sola entidad propietaria 0 controladora para proporcionar algún tipo de servicio de hospedaje a terceros, ya sea con carácter mercantil o no". (Ver Figura 5)

\section{Matriz para el ARS.}

Para extraer el grafo y los indicadores del ARS se utilizará el Pajek Versión 6.4.

Se resalta la inexistencia (en México) de estudios que abordan el estudio del Impuesto al Hospedaje desde el ámbito reticular-cognitivo $y_{1}$ por otro lado, la contribución de los análisis en redes de políticas públicas contribuyó de manera significativa para analizar esta variable.

En el proceso de la conformación reticular a través del ARS, la sistematización de las conexiones entre partes interesadas y actores que colaboran en el proceso de recaudación, gestión y aplicación del impuesto a través de la promoción turística son indispensables para la construcción de un cuadro relacional o matriz; la cual se detalla a continuación:

\section{(Ver Cuadro 3)}

De la matriz con las relaciones de colaboración integradas, se construyó la matriz adyacente para posteriormente construir el grafo (red). Una vez emitida la red, se realizó el análisis cuantitativo a través del cálculo de indicadores reticulares concentrados a continuación:

(Ver Cuadro 4) 
Cuadro 3: Relaciones de colaboración en el Impuesto al Hospedaje en la recaudación, gestión y aplicación a través de la promoción turística.

\begin{tabular}{|c|c|c|}
\hline SIGLAS & Stakeholder/ Actor & Establece relación con \\
\hline $\mathbf{H}$ & Sector Hotelero & $\begin{array}{l}\text { OCV, SHE, CFT, CF, F, } \\
\text { CCSTC, PT }\end{array}$ \\
\hline OCV & Oficina de Convenciones y Visitantes & $\begin{array}{l}\mathrm{H}, \mathrm{SHE}, \mathrm{CFT}, \mathrm{CF}, \mathrm{F}, \mathrm{CCSTC} \text {, } \\
\text { PT }\end{array}$ \\
\hline SHE & Secretaria de Hacienda Estatal & $\mathrm{H}, \mathrm{OCV}, \mathrm{CFT}, \mathrm{CF}, \mathrm{F}, \mathrm{CCSTC}$ \\
\hline CFT & Comisión de Fomento al Turismo & $\begin{array}{l}\text { H, PT, OCV, SHE, CF, F, } \\
\text { CCSTC }\end{array}$ \\
\hline CF & Comité Técnico Fideicomiso & $\begin{array}{l}\mathrm{H}, \mathrm{OCV}, \mathrm{SHE}, \mathrm{CFT}, \mathrm{CF}, \mathrm{F}, \\
\text { CCSTC }\end{array}$ \\
\hline $\mathbf{F}$ & Fidecomiso & OCV, SHE, CFT, CF \\
\hline CCSTC & $\begin{array}{l}\text { Cámaras de Comercio, Servicios y Turismo, } \\
\text { Cámaras de Industria y Confederaciones } \\
\text { (AMDEM, GMA, AMTAVE, AMAIT, } \\
\text { CANAPAT, USEM, AMHM, ADI, ANCH, } \\
\text { AIHET, FADEHI, AMDETUR, FHEHHM, } \\
\text { CANACINTRA, CNET, CPTM, } \\
\text { CONCANACO-SERVYTUR, CANIRAC, } \\
\text { SIEM. }\end{array}$ & $\mathrm{H}, \mathrm{PT}, \mathrm{OCV}, \mathrm{SHE}, \mathrm{CFT}, \mathrm{CF}, \mathrm{F}$ \\
\hline IE & Instituciones Educativas & $\mathrm{H}, \mathrm{OCV}, \mathrm{SHE}, \mathrm{CFT}$ \\
\hline PT & Proveedores turísticos diversos & $\mathrm{H}, \mathrm{OCV}, \mathrm{CFT}, \mathrm{CCSTC}$ \\
\hline
\end{tabular}

Fuente: Elaboración propia basada en análisis de stakeholders y actores del proceso del impuesto al hospedaje.

Cuadro 4. Matriz de Adyacencia. Impuesto al Hospedaje y Promoción turística.

\begin{tabular}{|c|c|c|c|c|c|c|c|c|c|c|}
\hline & $I$ & Ż & 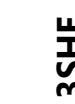 & 岁 & & Ü & 屯 & u & $\frac{\omega}{\infty}$ & 늠 \\
\hline $1 \mathrm{H}$ & & 0 & 1 & 1 & 1 & 1 & 0 & $\begin{array}{ll}0 & 1\end{array}$ & 1 & 1 \\
\hline $20 C V$ & & 1 & 0 & 1 & 1 & 1 & 1 & 1 & 0 & 1 \\
\hline 3SHE & & 1 & 1 & 0 & 1 & 1 & 1 & 1 & 0 & 0 \\
\hline 4CFT & & 1 & 1 & 1 & 0 & 1 & 1 & 1 & 0 & 1 \\
\hline $5 \mathrm{CF}$ & & 1 & 1 & 1 & 1 & 0 & & 1 & 0 & 0 \\
\hline $6 F$ & & 0 & 1 & 1 & 1 & 1 & 0 & 0 & 0 & 0 \\
\hline 7CCSTC & & 1 & 1 & 1 & 1 & 1 & & 0 & 0 & 1 \\
\hline 8IE & & 1 & 1 & 1 & 1 & 0 & & 0 & 0 & 0 \\
\hline 9PT & & 1 & 1 & 0 & 1 & 0 & & 1 & 0 & 0 \\
\hline
\end{tabular}

Fuente: Elaboración propia basada en análisis de stakeholders y actores del proceso del impuesto al hospedaje. 


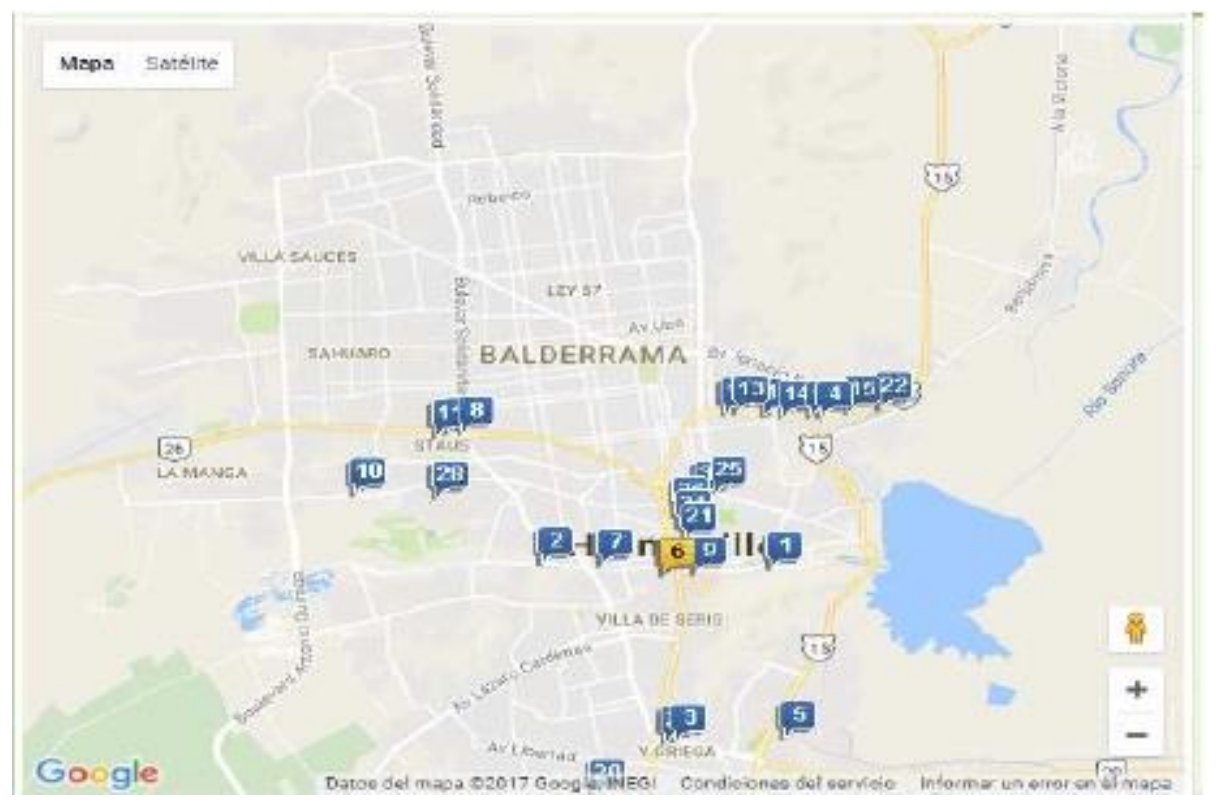

\section{Conclusiones}

Es notable la red de interacciones y de colaboración entre los diferentes actores que participan del sector público, privado, social, así como de las diversas cámaras de comercio, servicios y turismo, cámaras de industria y confederaciones que participan directa e indirectamente en el proceso de recaudación y gestión del impuesto al hospedaje y en la aplicación a través de la promoción turística.

Como se expuso en un inicio, los objetivos del presente trabajo se resumen en: 1 . Identificar actores, partes involucradas y acciones interdependientes en la recaudación, gestión pública y aplicación del impuesto al hospedaje en la promoción turística, 2) Presentar de manera gráfica las conexiones relacionales y regularidades; visualizando la cooperación y transferencia de recursos y 3) Mostrar el aporte teórico y metodológico a través del Análisis de Redes Sociales (ARS).

Lo antepuesto fue logrado a través del aporte teórico aplicable al ARS; así como la descripción de los diversos nodos presentes en el proceso señalado. Dicha reticularidad finalmente deriva de la conjunción de esfuerzos para el cumplimiento de objetivos y beneficios comunes que aportan valor basado en las experiencias de cada uno de ellos de tal manera que se genera una sinergia entre las aportaciones que actúan en el destino turístico que impacta la promoción.
No obstante lo anterior, en el análisis del proceso, se identificó que la disposición de información pública en estos procesos de gestión y aplicación del tributo aún no logra una completa transparencia, siendo necesaria la oportuna generación de indicadores para la medición, control y posterior toma de decisiones. En tal sentido, el ARS resulta altamente útil para la toma de decisiones, ya que permite clasificar a los diversos colaboradores del proceso en función de su vinculación directa o indirecta con la actividad promocional del destino y los administradores del tributo.

En contraparte, no es suficiente que exista colaboración a un nivel de obligatoriedad normativa, puesto que el flujo financiero del impuesto que es la base de interacción entre estos actores es notablemente operado por un actor principal que es el gobierno. El sector público que forma parte de este proceso, asume la financiación del proceso a través de fideicomisos creados para la gestión de la promoción turística, la cual, esencialmente existe para incidir como parte de un desarrollo local turístico.

Los marcos normativos son ejercidos por los individuos al interior de las organizaciones, por lo que los objetivos son logrados cuando los actores del proceso en una política pública se encuentran debidamente coordinados con el resto de los individuos e instituciones; por lo que en este trabajo se ha logrado capturar las colaboraciones entre actor-institución en un contexto de política pública. 
Por último, se resume la necesidad de profundizar en el análisis de la relación entre los sectores público y privado no solo para la promoción turística, sino para mitigar la opacidad en las finanzas públicas en el proceso de recaudación y aplicación del impuesto creado para promocionar el destino turístico y por ende redunde en la confianza del sector hotelero como colaboradorretenedor del tributo que genera la financiación; ya que la disponibilidad de la información pública para este estudio continua presentando un área de oportunidad que las partes involucradas deben tener presentes en sus procesos de colaboración.

\section{Bibliografía}

Adler-Lomnitz, Larissa (1975). Cómo sobreviven los marginados. Madrid: Siglo XXI.

Agranoff, Robert y McGuire, Michael (1998). "Multinetwork Management Collaboration and the Hollow State in Local Economic Policy". Journal of Public Administration Research and Theory, 8 (1), 6791.

Arenilla, Manuel \& Sánchez, Ana (2011). "El proceso modernizador de la Administración: Andalucía y Castilla y León". En M. Arenilla, Crisis y reforma de la Administración pública (págs. 139-161). Oleiros: Netbiblo.

Barnes, John (1954). Class and Cornrnitee in a Nonvegian Island Parish. En Humans Relations 7: 39-58

Blair, Robert (2002). Policy Tools Theory and Implementation Networks: Understanding State Enterprise Zone PartnershipsJournal of PublicAdministration Research and Theory, vol. 12, núm. 2, 2002, pp. 161-190

Börzel, Tanja (1998). "Organizing Babylon - On the different conceptions of Policy Networks". Public Administration, 76, 253-273.
Burt, Ronald (1980). Actor Interests in a Social Topology: Foundation for a Structural Theory of Action."; Sociological Inquiry, 1980, 50(2), pp. 107-132. http://onlinelibrary.wiley.com.ezproxy.uacj.mx/doi/10.1 $111 / \mathrm{j} .1475-$

682X.1980.tb00380.x/epdf?r3_referer=wol\&tracking_ac tion=preview_click\&show_checkout=1\&purchase_referr er=onlinelibrary.wiley.com.ezproxy.uacj.mx\&purchase site_license $=$ LICENSE_EXPIRED

Bott Elizabeth (1957). "Family and Social Networks". London: Tavistock.

Candace Jones, William, Hesterly\& Stephen Borgatti (1997). The Academy of Management Review. Vol. 22, No. 4 (Oct., 1997), pp. 911-945

Choi, Jin (2007). Governance Structure and Administrative Corruption in Japan: An Organizational Network Approach. Public Administration Review, vol. 67, núm. 5, 2007, pp. 930-942

Di-Maggio, Paul \& Powell, Walter (1991). El nuevo institucionalismo en el análisis organizacional. México. Fondo de Cultura Económica.

Duran, Citlalin (2013), Gobernanza para el sector turismo y su medición, Programa de Estadísticas y CST de la OMT. Serie de Documentos Temáticos STSA/IP/2013/01 (en línea), disponible en: http://statistics.unwto.org/es/content/documentos

Erdós, Paul \& Rényi, Alfréd (1960) "On the evolution of random graphs". Publcations of the Mathematical Institute of the Hungarian Academy of Sciences, 17 (5): 17-61

Freeman, Edward (1984). Strategic Management: A Stakeholder Approach. Ptman Press, Boston.

Freeman, Linton. (1989). "Social Networks and the Structure Experiment", en Freeman, L. C., D.R. White y A.K. Romney (eds.). Research methods in social network analysis, George Ma- son University Press, Fairfax, VA.

Freeman, Linton (2004). The development of social network analysis. A study inthe Sociology of Science. Vancouver. Empirical Press. 
Galaskiewicz, Joseph (1985). Social Organization of an Urban Grants Economy. New York: Academic Press.

Galaskiewicz, Joseph \& Wasserman, Stanley (1989). Mimetic and Normative Processes within an Interorganizational Field: An Empirical Test. Administrative Science Quarterly. 34: 454-480.

Granovetter, Mark (1973). "The Strength of Weak Ties," American Journal of Sociology 78, no. 6 (May, 1973): 1360-1380.DOI: 10.1086/225469

Hall, Michael (1999). "Rethinking Collaboration and Partnerships: A Public Policy Perspective". Journal of Tourism, 7 (3), 274-289.

Harary, Frank (1963). "Cosi Fan Tutte" - A Structural Study, Psychological Reports, 13 (2) 466-466. DOI: 10.2466/pro.1963.13.2.466

Hanneman, Robert y Riddle, Mark (2005). Introduction to social network methods [Online]. Available: http://faculty.ucredu/ hanneman/nettext/

Hanneman, Robert (2002). Introduction to social Network Methods. Riverside, USA: Departament of Sociology, University of California.

Hernández, G (2006). Diccionario de Economía. Editorial Universidad Cooperativa de Colombia. $1^{\text {a }}$ Ed 2006. p. 27. https://books.google.com.mx/books?id=pp1TliD_uNUC \&lpg=PA29\&ots=VulxCDLLFA\&dq=politica\%20fiscal \%20unam\&hl=es\&pg=PA29\#v=onepage \&q=politica\%2 Ofiscal\%20unam\&f=false

Herrero, Reyes (2000). "La terminología del análisis de redes. Problemas de definición y de traducción", en Política y Sociedad, núm. 33, 2000, pp. 199-206

Homans, George (1961) Social Behavior Its Elementary Forms. Nueva York: Harcourt, Brace \& World.

Knoke, David \& Yang, Song (2007). Social Network Analysis (2nd ed.). Sage Publications, Inc.

Martínez, Manuel (2015). De la cultura en las políticas públicas. Convergencia. Revista de Ciencias Sociales, Septiembre-Diciembre, 235-241.
Marsden, Peter \& Laumann, Edward (1984). Mathematical ideas in social structural analysis. Journal of Mathematical Sociology, 10:271-294

Mitchell, Clyde (1969) "The Concept and Use of Social Networks", en J. Clyde Mitchell (ed.), Social Networks in Urban Situations: Analyses of Personal Relationships in Central African Towns, Manchester, University Of Manchester -Institute For African Studies University Of Zambia, pp. 1-50.

Molina, José (2004). La ciencia de las redes. Apuntes de Ciencia y Tecnología, No 11, junio de 2004. Asociación para el Avance de la Ciencia y la Tecnología en España (AACTE). Recuperado de: http://revistaredes.rediris.es/recerca/jlm/ars/ciencia.pdf

Molina, José; Muñoz, Juan \& M. y Domenech, Miguel (2001). "Redes de publicaciones científicas. Un análisis de la estructura de coautorías", REDES- Revista hispana para el análisis de redes sociales. Vol.1, \#3, enero 2002.

Moreno, Jacob (1934). Who Shall Survive?: Foundations of Sociometry, Group Psychotherapy, and Sociodrama. Washington, D.C.: Nervous and Mental Disease Publishing Co. Reimpresoen 1953 (2a ed.) y en 1978 (3a ed.). Beacon, NY: Beacon House.

Molina, José Luis (2001), El análisis de redes sociales. Una introducción. Barcelona: Edicions Bellaterra. p. 13.

Newman, Mark (2003). "The structure and function of networks", SIAM Review 45, 167-256.Recuperado de: http://arxiv.org/abs/cond-mat/0303516/.

DOI: $10.1137 / S 003614450342480$

O'Toole, Laurence (1997). "Treating Networks Seriously: Practical and Research-Based Agendas in Public Administration". Public Administration Review, 57 (1), 45-52.

Porras, Francisco (2007): "Teorías de la gobemanza y estudios regionales" en Secuencia, septiembrediciembre, p 163-189, México, D.F.

Porras, Francisco (2012). Gobernanza y redes de política pública en espacios locales de México, Gobernanza y redes de política pública en México en Francisco Porras (coord.), México, Instituto Mora, 2012, pp. 9-25. 
Provan, Keith \& Kenis Patrick (2008). Modes of Network Governance: Structure, Management, and Effectiveness. J Public Adm Res Theory (2008) 18 (2): 229-252. DOI: https://doi.org/10.1093/jopart/mum015

Provan, Keith. y Milward, Brinton (1995). "A preliminary theory of interorganizational network effectiveness: a comparative study of four community mental health systems". Administrative Science Quarterly, 40, 1-33.

Quiroga, Águeda (2003). Introducción al Análisis de datos reticulares. Prácticas con UCINET6 y NetDraw1. Departamento de Ciencias Políticas, Universidad PompeuFabra. Recuperado de: http://revistaredes.rediris.es/webredes/talleres/redes.htm Consultado el 26 de marzo de 2017.

Ramírez, Edgar (2016). Análisis de Redes Sociales para el estudio de la gobernanza y las políticas públicas. México: Centro de Investigación y Docencia Económica, A.C.

Rendón, Roberto, Muñoz, Manrrubio. \& Altamirano, Reyes (2007). Identificación de actores clave para la gestión de la innovación: el uso de redes sociales (1a ed.) Chapingo: Universidad Autónoma de ChapingoCiestaam/PIIAll.

Reynoso, Carlos (2008). Hacia la complejidad por vía de las Redes. Nuevas lecciones epistemológicas. Desacatos, N 28, México, setiembre-diciembre 2008. Recuperado http://www.scielo.org.mx/pdf/desacatos/n28/n28a4.pdf

Rhodes, Roderick (1997). Understanding governance: policy networks, governance, reflexivity, and accountability. Open University Press, 1997. ISBN: 0335197280, 9780335197286

Rhodes, Roderick (2000). Governance and Public Administration, Jon Pierre (ed), Debating Governance: Authirity, Steering and Democracy, Oxford University Press, Oxford. pp. 54-90

Ruiz, Alejandro (2005). Gratificación mediante Pajek [mimeo]. Laboratorio de redes UNAM, México. http://revista-redes.rediris.es/pdf-vol6/vol6_4.pdf
Sánchez, P.G. 2008. La implementación de programas públicos a través de redes de política en los municipios mexicanos: dos casos de estudio, Tesina (Maestría en Administración y Políticas Públicas), México, CIDE

Scott, John (2017) Social Network Analysis.

Recuperado de: https://books.google.com.mx/books?id=i5EmDgAAQB AJ\&pg =PR2\&dq =social +network+analysis + scott +4 th \& $\mathrm{hl}=$ es\&sa=X\&redir_esc=y $\# \mathrm{v}=$ onepage $\& \mathrm{q}=$ =social\%20net work\%20analysis\%20scott\%204th\&f=false

Simmel, Georg (1927). Soziologie: Untersunchungen uber die formen der vergeseeschaftung, and the Spanish translation, Sociología. Un estudio sobre las formas de socialización., (2 Vols.), Madrid, Revista de Occidente.

Sorensen, Eva \&Torfing, Jacob (2005). The Democratic Anchorage of Governance Networks. Scandinavian Political Srudies, vol. 28, núm. 3, 2005, pp. 195-218

Towsend, Wendy (2004). System Changes Associated with Criminal Justice Treatment Networks.

PublicAdministrationReview, vol. 64, núm. 5, 2004, pp. 607-617

Vargas, Jorge (2011). La calidad de la democracia y el estudio comparado de la democratización. Revista Latinoamericana de Política Comparada. ISSN: 1390 4248 • Julio 2011 • Volumen No. 5, pp. 67-94.

Wasserman, Stanley \& Faust, Katherine (1994). Social Network Analysis. Cambridge: Cambridge University Press.

Wasserman, Stanley \& Faust, Katherine (1999). Social Network Analysis. Methods and Applications. United States of America. Cambridge University Press.

Wasserman, Stanley \& Faust, Katherine (2013). Análisis de redes sociales: Métodos y aplicaciones. Madrid: Centro de Investigaciones Sociológicas.

Weber, Edward \& Khademian, Anne (2008). Wicked Problems, Knowledge Challenges, and Collaborative Capacity Builders in Notwork Settings.

PublicAdministrationReview, vol. 68, núm. 2, 2008, pp. 334-339 
Wellman, Barry (1998). A computer network is a social network. SIGGROUP Bulletin 19(3),41-45.

Zabaleta, Dionisio. 2008. La gestión de redes como una estrategia gubernamental de liderazgo contingente: dos proyectos de conservación del patrimonio cultural urbano en la Ciudad de México, Tesina (Maestría en Administración y Políticas Públicas), México, CIDE.

Zizaldra, Isabel (2010). Red transfronteriza en turismo, una exploración en Ciudad Juárez Chihuahua, México, El Paso Texas, Estados Unidos. Teoría y Praxis Vol. 8 pp.137-155.

\section{Referencias electrónicas}

Consejo de Promoción Turística de México (CPTM.). Manual de Organización: Glosario de términos. Recuperado http://www.cptm.com.mx/sites/default/files/manual_de_ organizacion_2014.pdf. P. 340-345

Cuenta Pública del Estado (2015). Recuperado de: http://isaf.gob.mx/index.php?option=com_content\&view $=$ article\&id $=252$ : calificacion\&catid $=1$ : latest -

news\&ltemid $=50$

DataTur. Banco de Datos Turísticos. (2017-2014) http://datatur.sectur.gob.mx/.

Diccionario Jurídico (2017). Recuperado de: https://www.diccionariojuridico.mx/?pag=vertermino\&i $\mathrm{d}=1842$

International Network for Social Network Analysis (INSNA 2017). Recuperado de: http://www.insna.org/

Ley de Cámaras Empresariales y sus Confederaciones (2017). Recuperado de: http://www.diputados.gob.mx/LeyesBiblio/pdf/LCEC.pd $f$

Ley General de Turismo (2017). Recuperado de: http://www.diputados.gob.mx/LeyesBiblio/pdf/LGT_17 1215.pdf

Ley de Hacienda del Estado de Sonora (2013-2017). Recuperado http://www.isaf.gob.mx/compendio/Estatal/Leyes/Ley\% 20009\%20De\%20Hacienda\%20del\%20Estado\%20de\%2 OSonora.pdf
Ley de Presupuesto de Egresos y Gasto Público Estatal (2009-2017). Recuperado de: http://www.isaf.gob.mx/compendio/Estatal/Leyes/LEY_ DEL_PRESUPUESTO_DE\%20EGRESOS_Y_GASTO _PUBLICO_ESTATAL.pdf

OCDE Estudios en Turismo (2017). OECD Tourism Policy Review of México. Versión en inglés: ISBN 9789264266568 / DOI: http://dx.doi.org/10.1787/9789264266575-en. Traducido al español por la Secretaría de Turismo, bajo acuerdo con la OCDE. Estudios de la Política Turística de México (2017), pp. 16, 18-19, 25.

Organización para la Cooperación y el Desarrollo Económico (OCDE, 2015). Recuperado de: http://uww.inegi.org.mx/est/contenidos/proyectos/cn/tur de: $\quad$ I

Sistema Integral de Información de Mercados Turísticos (SIIMT) del Consejo de Promoción Turística de México (2017). Recuperado de:

http://www.siimt.com/es/siimt/estructura_turistica

Reglamento de la Ley General de Turismo (2017). Recuperado de: http://www.diputados.gob.mx/LeyesBiblio/regley/Reg_L GT.pdf

Universidad Nacional Autónoma de México (UNAM 2017) Laboratorio de Análisis de Redes Sociales http://harary.iimas.unam.mx/ 